\title{
Sensitivity of a benthic, metazoan, biomass size spectrum to differences in sediment granulometry
}

\author{
Daniel E. Duplisea ${ }^{1, *}$, Aleksander Drgas ${ }^{2}$ \\ ${ }^{1}$ Department of Systems Ecology, Stockholm University, S-106 91 Stockholm, Sweden \\ ${ }^{2}$ Department of Oceanography, Sea Fisheries Institute, Kollataja 1, PL-81-332 Gdynia, Poland
}

\begin{abstract}
Benthic biomass size spectra of meiofauna and macrofauna (BBSS) were examined at 4 sites in the Askö area, on the Swedish coast of the northern Baltic Sea proper. The sites ranged in median sediment grain size from a coarse sand $(680 \mu \mathrm{m})$ to mud $(<63 \mu \mathrm{m})$. Previous empirical work and theory suggests that BBSS are bimodal where sediment granulometry permits the existence of both fauna that live interstitially and those that burrow; each biomass mode reflects constraints on organism body size for each activity. Two hypotheses based on this theory are tested here: (1) BBSS are bimodal in sediments which support both an interstitial and burrowing fauna and (2) the biomass trough between modes of the spectrum changes consistently with sediment grain size. None of the BBSS from any of the sites were bimodal; thus, the first hypothesis was rejected. Shapes of spectra varied somewhat among sites but showed no consistent difference related to sediment granulometry; thus, the second hypothesis was rejected. To further test these hypotheses, spectra were confined to infauna by removing the surface sediment layer $(0$ to $1 \mathrm{~cm})$, thereby removing epibenthic fauna. Both hypotheses were once again rejected when the spectra consisted of only infauna.
\end{abstract}

KEY WORDS: Community structure Grain size - Size distribution - Invertebrate - Meiofauna Macrofauna

\section{INTRODUCTION}

Metazoan benthic biomass size spectra (BBSS), total organism biomass plotted over individual body size, were first described as bimodal for temperate marine benthic communities (Schwinghamer 1981, 1983). The theory put forth to explain this widespread pattern was that within sediments 2 habitats exist that are suitable for benthic eukaryotes: interstitial and super-sediment-grain. Bimodal BBSS were said to be reflections of the structure that these 2 habitats forced on benthic organism size. That is, only organisms within a certain size-range could live interstitially and there would be an optimum body size at the midpoint of this range. Similarly, there would be a lower limit to the size of

\footnotetext{
- Present address: Lowestoft Laboratory, Pakefield Road, Lowestoft, Suffolk, NR33 OHT, United Kingdom.

E-mail: d.duplisea@cefas.co.uk
}

organisms that could manipulate sediment grains. It was shown that the sizes of organisms in these modes and intervening trough corresponded to the commonly recognised benthic groups meiofauna and macrofauna, which are operationally defined by their body size. These early BBSS suggested that the operational definitions of meiofauna and macrofauna had real ecological meaning at the community scale regardless of taxonomic structure.

Schwinghamer's (1981) explanation implies that benthic community size structure should be highly sensitive to sediment granulometry, most notably to interstitial pore size. However, Schwinghamer (1981) did not analyse his size spectra in relation to a measure of sediment grain size, though site descriptions suggest that a range of sediment types were sampled (range of sediment silt/clay fraction between 0.8 and $49 \%$ ). Nevertheless, a similar bimodal eukaryotic spectrum was found in all locations. In other studies, species size spectra from sediments ranging from fine mud to 
coarse sand at several locations on the English coast and a South African location were all bimodal and of similar shape (Warwick 1984). This result was not a contradiction of Schwinghamer's observations but suggested that different factors may control the species component than control the biomass component of marine benthic community size structure. Both species and biomass size spectra of small metazoans from finegrained lake sediments were found to be an increasing function of individual body size, creating unimodal spectra (Strayer 1986). The results of Warwick (1984) and Strayer (1986) taken together suggest that observed BBSS patterns may be more closely related to the species size distribution than to sediment granulometry, and that species size distribution is rather insensitive to sediment granulometry.

Considerable work has accumulated on benthic organisms in relation to the physical environment of the sediments (see review of Snelgrove \& Butman 1994), indicating that sediment community response to sediment grain size is equivocal, and that numerous other non-trophic and trophic factors also affect community structure. Non-trophic factors such as sediment water content, organic $\mathrm{C}$ and $\mathrm{N}$ content, porewater oxygen concentration and the sediment redox environment are all important in determining benthic community structure (Jansson 1967, Williams 1972, Snelgrove \& Butman 1994). Sediment chemistry and particularly oxygen seem to affect benthic community structure in a more discontinuous manner, with organisms responding at threshold concentrations (Jansson 1967 , Strayer et al. 1997): organisms will be absent below certain oxygen concentrations but above those concentrations a normal community will develop. Much of the past success in attributing benthic community structure to sediment granulometry has probably occurred because so many sediment characteristics are correlated (Duplisea 1998), including sediment grain size (Snelgrove \& Butman 1994), and most are a result of the hydrodynamic environment. As such, the apparent community response to sediment grain size is probably a response to numerous other correlated sediment factors as well. This does not lend support to Schwinghamer's (1981) theory, which is based solely on sediment grain size (more precisely, sediment pore space size) as the forcing factor. The theory, however, is intuitively pleasing in its simplicity and has supportive theoretical underpinnings in terms of organisms' perception of their environment's dimensions (Silvert 1996). As a result, the sediment grain size argument is often quoted as the reason for a bimodal BBSS, e.g. (Holling 1992), though numerous empirical studies have shown non-bimodality and the theory has not been directly tested. As pointed out by Macpherson \& Gordoa (1996), work on biomass size spectra is still novel and few replicated studies have been conducted leading to much speculation as to size spectra patterns and their causes.

The present work has as its primary goal the examination of benthic organism size spectra in relation to sediment granulometry as a test of the theory proposed by Schwinghamer (1981). Using data collected from 4 locations in the Baltic Sea, near Stockholm, Sweden, we tested 2 hypotheses derived from Schwinghamer's (1981) work: (1) BBSS are bimodal in sediments which support both an interstitial and burrowing fauna (2) BBSS patterns change consistently with sediment grain size; this is a reflection of the change in body size of interstitial and burrowing organisms in response to the resultant changes in sediment constraints.

\section{METHODS}

Study sites. All sampling was conducted near the Asko Laboratory $\left(58^{\circ} 49^{\prime} \mathrm{N}, 17^{\circ} 38^{\prime} \mathrm{E}\right)$ on the Swedish Baltic Sea coast between 7 and 23 April 1997. The Askö area is an archipelago of many small islands and rocky shoals and a few large islands. Shallow coastal waters in this area have a stable salinity of between 6 and $7 \%$. In April, waters are not stratified and vary in temperature between about 3 and $5^{\circ} \mathrm{C}$. Most shallow coastal waters here remain oxic throughout the year.

A preliminary survey of sediments from waters between 10 and $15 \mathrm{~m}$ depth and within about a $5 \mathrm{~km}$ radius of the Asko laboratory was conducted. Sediments were sampled using a van Veen grab and a homogeneous sub-portion was taken from these grabs and wet sieved through a series of nested steel sieves for median sediment grain size determination. From a survey of 14 sites, 4 were chosen because of their grain size properties. Sites were selected where sediments were relatively well sorted, and ranged in size (among sites) from coarse sand to mud/clay (Holme \& McIntyre 1984).

Stn 1: Coarse sand site at $12 \mathrm{~m}$ depth with a median grain size of about $0.68 \mathrm{~mm}$ (Table 1). Bottom topogra. phy at this station was described by SCUBA divers as being markedly wavy. The wave length was between 50 and $70 \mathrm{~cm}$ and wave height was 5 to $7 \mathrm{~cm}$. Trough areas between waves often contained loose-lying clumps (druses) of blue mussels Mytilus edulis.

Stn 2: Medium sand site at $12 \mathrm{~m}$ depth with a median grain size of $0.56 \mathrm{~mm}$ (Table 1). Bottom topography at this station was similar to that of Stn 1 except that the wave length was between about 30 and $50 \mathrm{~cm}$ and wave height was 3 to $5 \mathrm{~cm}$. Mytilus edulis druses, though present in the troughs, were smaller and less frequent than at Stn 1. 
Table 1. Environmental characteristics of sampling sites. C: organic carbon; $\mathrm{N}$ : organic nitrogen; $\mathrm{H}_{2} \mathrm{O}$ : water content; QD: quartile deviation of sediment grain size distribution; skewness: skewness of sediment grain size distribution; dw: dry weight; ww: wet weight. Values for grain size, $\mathrm{QD}$ and skewness are replicate means $\pm \mathrm{SE}$ (3 replicates, except Stn 1, which has 2 replicates)

\begin{tabular}{|c|c|c|c|c|c|c|c|c|}
\hline Stn & $\begin{array}{l}\text { Depth } \\
\text { (m) }\end{array}$ & $\begin{array}{c}C \\
(\% d w)\end{array}$ & $\begin{array}{c}N \\
(\% d w)\end{array}$ & $\begin{array}{c}\mathrm{H}_{2} \mathrm{O} \\
(\% \text { ww })\end{array}$ & $\begin{array}{c}\text { Porosity } \\
(\% \text { volume })\end{array}$ & $\begin{array}{l}\text { Median grain } \\
\text { size }(\mathrm{mm})\end{array}$ & $\begin{array}{c}\mathrm{QD} \\
\phi(\mathrm{mm})\end{array}$ & Skewness \\
\hline 1 & 12 & 0.035 & 0.003 & 17 & 32 & $0.680 \pm 0.10$ & $0.49 \pm 0.07$ & $0.01 \pm<0.01$ \\
\hline 2 & 14 & 0.097 & 0.012 & 21 & 39 & $0.560 \pm 0.30$ & $0.49 \pm 0.04$ & $0.05 \pm 0.02$ \\
\hline 3 & 12 & 0.350 & 0.041 & 25 & 46 & $0.160 \pm 0.10$ & $0.65 \pm 0.03$ & $-0.07 \pm<0.01$ \\
\hline 4 & 13 & 4.987 & 0.706 & 78 & 75 & $<0.063$ & - & - \\
\hline
\end{tabular}

Stn 3: Fine sand site at $13 \mathrm{~m}$ depth with a median grain size of $0.16 \mathrm{~mm}$ (Table 1). This station had a flat small-scale topography but sloped toward deeper water. A firmly packed clay layer below about $5 \mathrm{~cm}$ depth underlies the fine sand at this station.

Stn 4: Mud site at $14 \mathrm{~m}$ depth with a median grain size of $<0.06 \mathrm{~mm}$ (Table 1 ). The station was very flat topographically. Sediments from this area were brown in colour and appeared well oxygenated and without the odour of sulphides.

Sample collection and preservation and organism extraction. Core samples were collected from Stns 1, 2 and 3 by SCUBA divers on 21 April 1997 and from Stn 4 with a modified Kajak corer (Blomqvist \& Abrahamsson 1985) on 17 April 1997. From each station, a total of six, $8 \mathrm{~cm}$ diameter cores were taken to a sediment depth $>12 \mathrm{~cm}$. For Stns 1 and 2, 2 cores were taken from the wave troughs, 2 from the wave crests and 2 from the mid-wave position with reference to the bottom topography. Divers took replicate cores at least $3 \mathrm{~m}$ away from the closest replicate, and we assume that at least this distance separation also held for sampling with the Kajak cores. Core samples were taken back to the lab for treatment within $3 \mathrm{~h}$ of collection.

Of the 6 cores, 5 were used for faunal analysis and the sixth core was kept for characterisation of the sediment ( $C$ and $N$, porosity, water content; described in greater detail in 'Sample processing'). Of the 5 faunal cores, 3 were cut into $1 \mathrm{~cm}$ depth strata to a depth of $10 \mathrm{~cm}$ and preserved in $10 \%$ formalin stained with Rose Bengal. The top $10 \mathrm{~cm}$ of the 2 remaining faunal cores was preserved as above. Overlying water from cores was siphoned onto a $40 \mu \mathrm{m}$ sieve and washed into the preserved sample and the $0-1 \mathrm{~cm}$ fraction where applicable.

At each station, three $0.1 \mathrm{~m}^{2}$ van Veen grab samples were collected for macrofauna and live-sieved with seawater through 4,2 and $0.5 \mathrm{~mm}$ steel sieves. Sieved samples from Stns 3 and 4 were preserved in 10\% formalin and stained with Rose Bengal. Sieved samples from Stns 1 and 2 were treated differently because a considerable amount the sediment remained after sieving (up to $3 \mathrm{~kg}$ ).
Organisms from van Veen grab samples from Stns 1 and 2 were extracted from sediments with a combination of sieving and a shaking-decantation method. After sieving live samples, a $200 \mathrm{ml}$ portion of the remaining sediment was put in a plugged coring tube ( $8 \mathrm{~cm}$ diameter, $50 \mathrm{~cm}$ long), shaken and then the overlying water was decanted (Elmgren \& Radziejewska 1989), causing lower density organisms to remain in suspension while the sand quickly sank. The results of each decantation were visually inspected and the procedure was repeated at least 3 times, until no organisms were found in the supernatant.

The shaking-decantation procedure was highly efficient for soft-bodied organisms but less so for calcareous organisms; therefore, we picked the calcareous organisms (mainly hydrobids) from the entire sample if not too time consuming. Otherwise, at least 2 random subsamples of the leftover sediment were taken, and the subsample's organism density was related to the weight of the subsampled sediment, assuming this density was proportional to the weight of the total sample. This method of subsampling was used for only 4 of the 5 grab samples from Stn 1. All organisms were preserved in $10 \%$ formalin.

In the laboratory, preserved meiofauna samples were sieved through 40 and $500 \mu \mathrm{m}$ sieves. Organisms from the sediment fraction remaining on the $500 \mu \mathrm{m}$ sieve were picked out under a dissecting microscope. Organisms in the sediment fraction remaining on the $40 \mu \mathrm{m}$ sieve were extracted using a Ludox flotation method which is $>90 \%$ efficient for extraction of most meiobenthic organisms (Ólafsson \& Elmgren 1997). To be certain that all organisms were extracted, the residual sediment after each extraction was closely examined and the organisms were picked out. Sediment remaining after Ludox extraction was saved for later analysis of sediment grain size.

Sample processing. Most organisms were measured under a dissecting microscope using computerised image analysis. Molluscs, some polychaetes and amphipods were usually measured using image analysis without magnification on a light table. Organism dimensions were measured and used to calculate 
weight or volume, either from published relationships (Ankar \& Elmgren 1976, Rumohr et al. 1987, Feller \& Warwick 1988), or by assuming that organism shapes conformed to simple geometric shapes and calculating their volumes as such. Organism wet weight was calculated from volume assuming a density of $1.13 \mathrm{~g} \mathrm{~cm}^{-3}$.

Usually all macrobenthic individuals were measured, but some very abundant taxa such as nematodes and oligochaetes were subsampled. In such cases, at least 100 randomly selected individuals of each taxon were measured and the rest were counted, and a density subsampling factor applied to that taxon accordingly.

Macrofauna were determined to the species level for all taxa except hydrobids and oligochaetes. In the meiofauna only major taxa, such as nematodes, harpacticoid copepods, oligochaetes, ostracods, etc. were distinguished.

Samples for sediment grain size were dry-sieved in a shaker through a stack of steel sieves $(2.000,1.000$, $0.500,0.250,0.125,0.063$ and $<0.063 \mathrm{~mm}$ ). Grain size samples were taken from the cores from which meiofauna had been extracted. After extraction of meiofauna the residual sediment was thoroughly washed on a $40 \mu \mathrm{m}$ sieve to remove excess Ludox, then oven dried at $60^{\circ} \mathrm{C}$ and stored dry until analyses could be performed. Sediment grain analysis on meiofauna cores was done only on samples from Stns 1,2 and 3, where the fraction of sediments $<0.063 \mathrm{~mm}$ was less than $10 \%$ of the total sediment weight (determined from site selection sieving analysis).

Porosity was determined by taking slices of known volume from 5 different depth strata of the sixth sediment core. These samples were weighed and then dried at $65^{\circ} \mathrm{C}$ for $10 \mathrm{~h}$ and reweighed. Porosity $(\%$ volume) was calculated as the ratio of water volume (weight) to fresh sediment volume. Water content ( $\%$ wet weight) was calculated as the ratio of sediment water weight to fresh sediment weight. These dried samples were then used for $\mathrm{CHN}$ analyses. For $\mathrm{CHN}$ analysis the sample was ground with a pestle and mortar, soaked in $0.1 \mathrm{MHCl}$ for several hours to remove carbonates and redried at $65^{\circ} \mathrm{C}$ for $10 \mathrm{~h}$. A known weight (20 to $80 \mathrm{mg}$ ) of $\mathrm{HCl}$-treated ground sample was put in tin cups and analysed with a Leco $\mathrm{CHN} 900$ for carbon and nitrogen content. An average of all depth strata for porosity water content and $\mathrm{C}$ and $\mathrm{N}$ values was taken to obtain a single value to characterise each sampling station.

Data analysis. BBSS were constructed using $\log _{2}$ groupings of organism wet weight $(\mu \mathrm{g})$ on the $x$-axis and $\log _{10}$ wet biomass $\left(\mathrm{g} \mathrm{m}^{-2}\right)$ on the $y$-axis. The $\log _{2}$ weight-class represents the nominal organism weight in the class. For example, the biomass in weight-class 7 represents the biomass of all organisms in the wet weight range $\geq 2^{7}$ to $<2^{8} \mu$ g or $\geq 128$ to $<256 \mu$ g. Organism body size spanned 30 weight-classes in this study ranging from $2^{-7}$ to $2^{22} \mu$ g wet weight.

Differences in BBSS among sites which allowed the incorporation of replicates were tested using 1 factor multivariate analysis of variance (MANOVA), where weight-class biomasses in the BBSS were considered dependent variables for testing the effect of location. To overcome problems of ill-conditioned matrices, the 30 BBSS weight-classes were combined into 6 weightclasses. That is, the biomasses in each set of 5 adjacent weight-classes were summed, and therefore the MANOVA model had 6 dependent variables: $(-7$ to -3$)$, ( -2 to 2$)$, ( 3 to 7$),(8$ to 12$),(13$ to 17$)$, and (18 to 22$)$, where numbers in parentheses are the inclusive weight-class endpoints defining each dependent variable. MANOVA assumptions of homoscedasticity and normality were tested on square-root transformed data with Levene's univariate test on all dependent variables and by examination of normal probability plots. The dependent variable of summed biomass in the weight-classes 18 to 22 (inclusive) was marginally heteroscedastic but all other variables satisfied assumptions.

\section{RESULTS}

All locations showed the steepest increase in biomass from weight-class -5 to a small peak at weightclass 0 or 2 (Fig. 1). The 2 coarse-grained sediment station (Stns 1 and 2) spectra first peaked at weight-class 2 while the fine sand and mud station (Stns 3 and 4) spectra first peaked at weight-class 0. After this initial peak, there was a shallower trend towards increasing biomass with body size. Replicate variability in core spectra was low below weight-class 11 and was low in several larger weight-classes as well. Patterns were duplicated in grab and core spectra between weightclasses 8 and 11 at all locations and a greater range of duplication was found at most locations. At Stn 4, the grab sampled a lower biomass than the corer, creating a dip in the combined gear spectrum at weight-class 10 for this station (Fig. 1, bottom panel). Generally, though, duplication of patterns in overlapping sampling size ranges indicated that the patterns were not due to gear sampling artefacts.

The 2 coarsest sediment stations (Stns 1 and 2) showed a biomass bump between weight-classes 10 and 12 which was much smaller in the fine sand station (Stn 3) spectrum and absent in the mud station (Stn 4) spectrum. This bump was due a preponderance of oligochaetes and hydrobids in this size interval. After this oligochaete bump, both stations showed an increase in biomass that was due to the presence of the bivalves Mytilus edulis and Macoma balthica. The lat- 
ter was present at all stations, while $M$. edulis was present at only the 2 coarse-grained sediment stations. Variability of the grab spectrum in the large bivalve range (weight-classes 19 to 22, inclusive) at Stns 1 and 2 was high. Large bivalves were heterogeneously distributed at these stations and therefore their numbers per grab varied relatively more between replicates than for smaller organisms.

MANOVA indicated that there was a significant difference (model) between spectra when weight-classes were summed into 6 groups $(5$ adjacent weight-classes summed) (model: Lambda $=0.0276$; Rao's $\mathrm{R}=4.4906, \mathrm{df}$ $1,2=18,31 ; \mathrm{p}=0.00013$ ) on square root transformed data. Post hoc tests indicated that significant differences occurred toward the small and large body sizes of the spectra but the middle weight-classes $(-2$ to 7$)$ were not significantly different (Table 2, Fig. 1). Stn 4 had a significantly higher biomass of small organisms, while generally a lower biomass of the larger organisms, relative to other stations. Stn 1 had a higher biomass of organisms in the weight-class range 8 to 12 (inclusive) than Stns 3 and 4 but was not different than Stn 2. Stn 1 had a high oligochaete and hydrobid biomass in the 8 to 12 weight-class range compared to Stns 3 and 4 . Of the 36 possible post hoc tests performed 16 permutations of the 4 locations $\times 6$ dependent variables), 7 were significant and 6 involved Stn 4, suggesting that the spectrum from this mud station is the most unique station of the 4 sampled.

Fig. 1 Biomass size spectra of benthic meiofauna and macrofauna in the top $10 \mathrm{~cm}$ of sediment from 4 sites differing in sediment granulometry in the Askö area, Baltic Sea. Lines connect mean values; error bars represent 1 standard error $(N=5$ at all locations). Bottom panel shows combined gear spectra. Core $=50 \mathrm{~cm}^{2}$ core sample, grab $=0.1 \mathrm{~m}^{2}$ van Veen grab sample. md: mean diameter. Note log scaling on axes
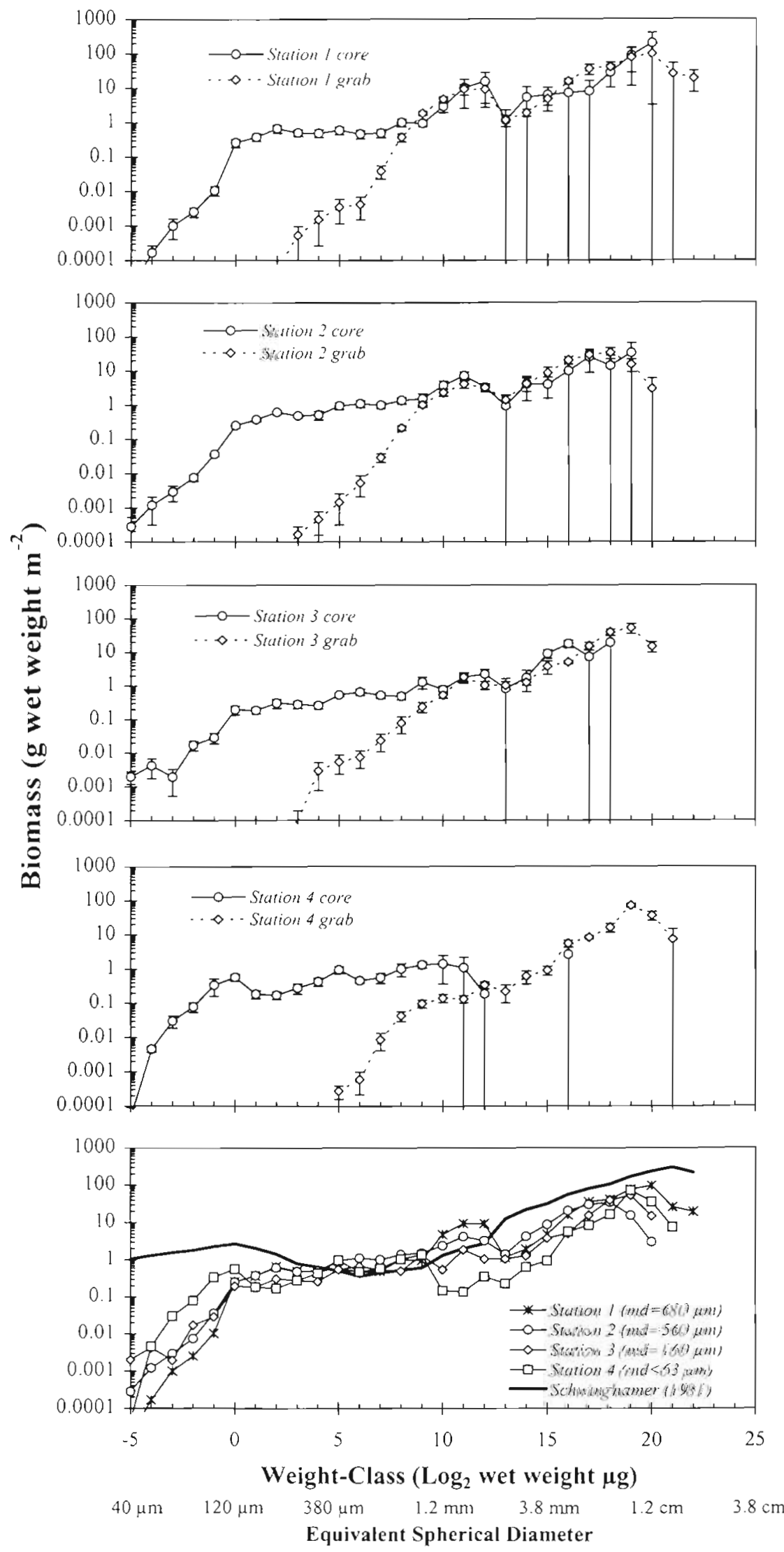
Table 2. Results (p-values) of Tukey HSD post hoc tests of the MANOVA model (effect $=$ location) between square root transformed summed weight-class biomass dependent variables between stations. Summed weight-class intervals are inclusive. Only significant results are reported; there were no significant differences in the weight-class intervals ( -2 to 2$)$, ( 3 to 7$)$ and (18 to 22). Numbers in 'test' column refer to stations. $\mathrm{N}=5$ for all tests

\begin{tabular}{|cccc|}
\hline Test & $\begin{array}{c}\text { Post hoc test } \\
\text { weight-classes } \\
-7 \text { to }-3\end{array}$ & $\begin{array}{c}\text { Post hoc test } \\
\text { weight-classes } \\
8 \text { to } 12\end{array}$ & $\begin{array}{c}\text { Post hoc test } \\
\text { weight-classes } \\
13 \text { to } 17\end{array}$ \\
\hline 1 vs 3 & - & 0.01 & - \\
4 vs 1 & 0.001 & 0.002 & 0.044 \\
4 vs 2 & 0.003 & - & 0.02 \\
4 vs 3 & 0.023 & - & - \\
\hline
\end{tabular}

Combined spectra (Fig. 1, bottom panel) show that up to weight-class 9 , shapes were quite similar between stations, but absolute biomass varied. After weight-class 9 , spectra shapes reflected taxonomic properties of the community such as the presence of large oligochaetes and bivalve biomass. This effect is partially due to combining spectra from the 2 gear types at this point, but also appears in spectra obtained using a single gear over this region in this size range. Superimposing Schwinghamer's (1981) data on these data shows that these spectra are not similarly bimodal, though there are biomass differences in our data of the same magnitude as those in Schwinghamer (1981). The pattern that best describes the spectra pattern found in this study is increasing biomass with increasing body size with little evidence of consistent differences between shapes of spectra relative to sediment granulometry.

BBSS were also constructed for all stations with the surface $1 \mathrm{~cm}$ removed to retest the hypotheses on only infaunal organisms. Core spectra with the 0 to $1 \mathrm{~cm}$ sediment layer spectrum removed from the depth-integrated spectrum (Fig. 2) did not show marked differences from those of the entire benthos. Stn 4 differed most when the 0 to $1 \mathrm{~cm}$ layer was removed, as a deep biomass trough occurred across weight-classes 1 to 3 (inclusive). Taxonomic analysis of the spectrum showed that harpacticoid copepods and nematodes had a 44 and $35 \%$ higher biomass, respectively, in the 0 to 1 $\mathrm{cm}$ stratum than at all other depth strata combined at Stn 4. Most of the biomass discrepancy, however, was due to the biomass of small, unidentified stained objects in the 0 to $1 \mathrm{~cm}$ stratum which was 24 -fold higher than in all other strata combined. This classification of organisms encompasses amorphous staining objects, which consist of a combination of turbellarians, gastrotrichs, protozoans, naked foraminiferans and eggs of epibenthic and planktonic crustaceans

There were no significant differences between core spectra with the surface layer removed (MANOVA, p >

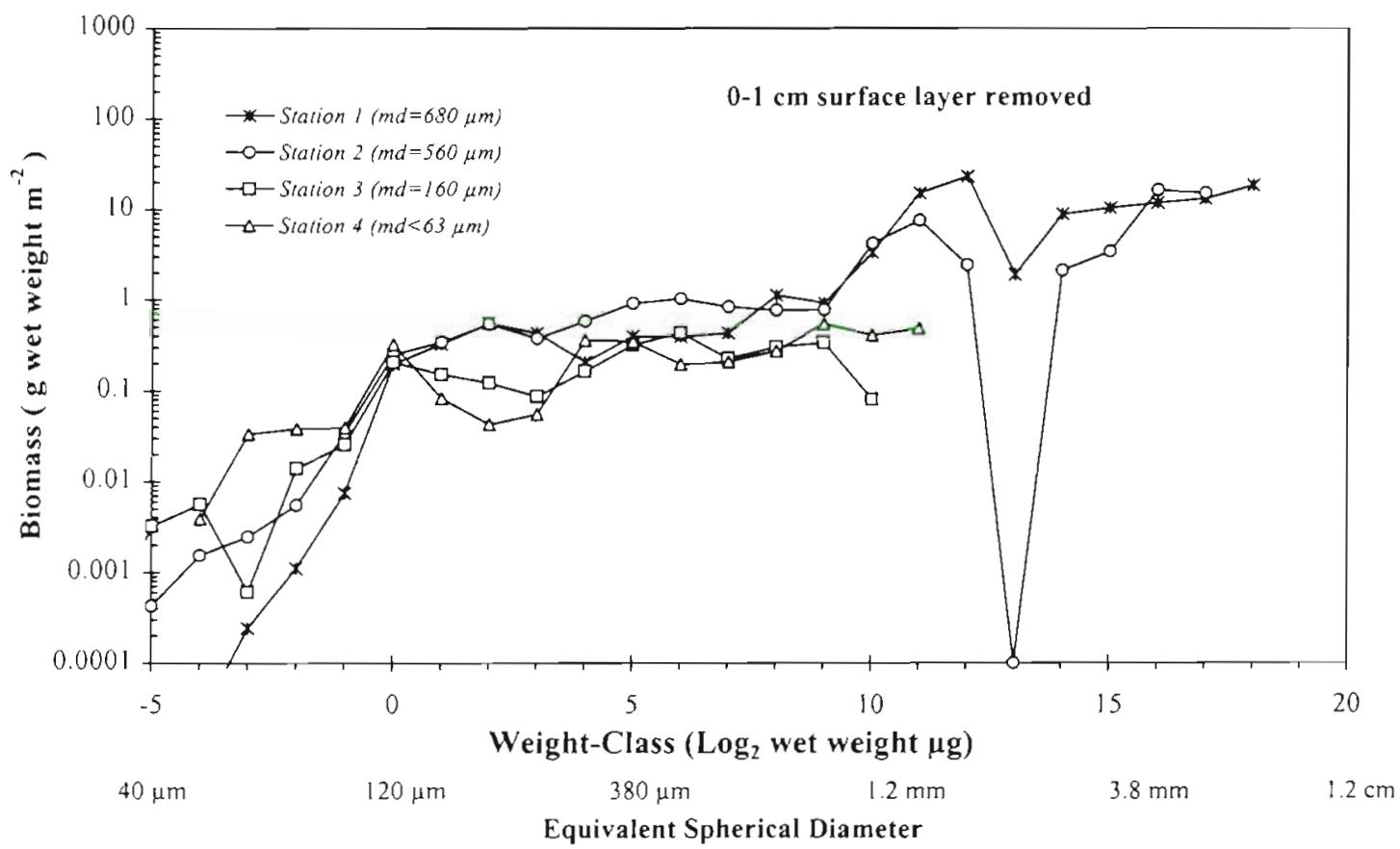

Fig. 2. Average biomass size spectra of meiofauna and macrofauna collected by a $50 \mathrm{~cm}^{2}$ core sampler in the 1 to $10 \mathrm{~cm}$ sedıment depth strata (surface $1 \mathrm{~cm}$ removed) from 4 sites differing in sediment granulometry in the Askö area, Baltic Sea. Points represent means of 3 replicates. md: mean diameter. Note log scaling on the axes 
$0.05)$ when 5 adjacent weight classes were summed to give 4 dependent variables. However, when only 4 or 3 adjacent weight-classes were summed, Stn 3 had a significantly higher biomass of the smallest organisms (< weight-class 4 ) than other stations. Generally, there were fewer significant differences between stations once the 0 to $1 \mathrm{~cm}$ surface layer was removed than when it was included.

\section{DISCUSSION}

BSSS patterns in different sediment types in the Askö area are not bimodal and there is no clear trough separating interstitial and burrowing organisms as described by Schwinghamer (1981). Our spectra, in contrast to those of Schwinghamer (1981), tend to show an irregular increase in biomass with body size to a peak near the largest weight-class. Similarly, we did not find differences in shapes of BBSS in the Askö area that were clearly related to sediment granulometry.

The Stn 4 spectrum was the most different from other sites. Schwinghamer (1981) described his trough region as a result of sediment granulometry. As sediments sampled at the 4 stations were of granulometry similar to those sampled by Schwinghamer, it is reasonable to expect a similar sort of trough appearing in these Askö sites; however, no similar trough was found. Only the mud station (Stn 4) spectrum showed a trough that consisted of several points (between weight-classes 2 and 4 ), yet this is the only sediment sampled which is not capable of supporting an interstitial fauna (lower limit $=120 \mu \mathrm{m}$ median grain size; Weiser 1959). Hence, a trough at the mud station is not consistent with Schwinghamer's theory. Other differences occurred in the larger weight-classes (8 to 17) between Stn 4 and Stns 1 and 2. These differences are due to the oligochaete/hydrobid-bivalve bump (described below) present in this size range at Stns 1 and 2 but not Stn 4 , rather than direct granulometric influences.

A shift in a trough region to a smaller body size with decreasing sediment grain size is an implicit prediction of Schwinghamer's theory; however, a shifting trough is not evident in this study. More readily interpretable differences between stations' spectra instead seem to be due to the presence or absence of some organisms. The presence of these organisms is to some degree dependent upon grain size, but in a threshold-like manner where mussels Mytilus edulis are present only in areas where they have a suitable substrate for attachment of their byssal threads. Similarly hydrodynamics is likely an important factor determining community structure as suspension feeders will be present only in areas with water movement sufficient to pro- vide them with food. Sediment grain size is a result of hydrodynamics (Snelgrove \& Butman 1994). As a result, distinguishing the effects of hydrodynamics and grain size is difficult and they are not naturally exclusive.

Empirical studies of BBSS have produced equivocal results as to a 'universal' spectrum shape. Some marine and limnic environments have shown a bimodal spectrum (Schwinghamer 1983, Gerlach et al. 1985, Warwick \& Joint 1987, Poff et al. 1993), while some have shown a more unimodal spectrum (Strayer 1986, Morin \& Nadon 1991, Bourassa \& Morin 1995). Hanson et al. (1989) found a bimodal spectrum; however, both modes occur entirely within the macrobenthic size ranges and do not reflect differences sensu Schwinghamer (1981). Poff et al. (1993) found a bimodal spectrum (sensu Schwinghamer 1981) in stream BBSS but since they assigned characteristic weights to meiobenthic taxa, their BBSS are largely a reflection of community taxonomic structure. Also, bimodality in Poff et al.'s (1993) spectrum appears at only some locations but combining data resulted in a bimodal spectrum. In light of the methods used by Poff et al. (1993) and evidence contrary to a lotic, limnic, bimodal spectrum (Morin \& Nadon 1991, Bourassa \& Morin 1995), it seems unlikely that bimodality is a widespread feature of stream BBSS.

Stns 1 and 2 both show a biomass bump between weight-classes 10 and 12. Taxonomic analysis of this bump indicates that this is primarily due to numerous oligochaetes and hydrobids in that size range. After weight-class 13 , biomass increased again, primarily due to an increase in bivalve biomass. These biomass modes with an intervening trough between bivalves and oligochaetes and hydrobids does not reflect an interstitial versus burrowing shift, since average oligochaete and hydrobid width at Stns 1 and 2 was much larger than the median pore diameter, which is about $10 \%$ of the median grain size (Williams 1972). All of these organisms must therefore be burrowers and the division in the spectrum at this point primarily reflects a change in taxonomic structure. Reducing the biomass of calcareous organism by $40 \%$ to make living tissue biomass comparable with the oligochaetes, reduces this bump somewhat but does not entirely eliminate it. Removal of the surface layer where most of the Mytilus edulis are found also smoothes the spectrum somewhat, but all other taxa persist in deeper layers so the structure remains.

Removal of the surface layer $(0$ to $1 \mathrm{~cm})$ to exclude epibenthic organisms did little to change the interpretation of spectra among the stations. This test was made because Schwinghamer's (1981) theory referred particularly to benthic infauna. Furthermore, it has been shown for benthic crustacean communities in 
subtropical seagrass beds that epibenthic crustaceans taking refuge in the structure of the overhanging seagrass fill the biomass trough reported by Schwinghamer (1981) while the pure infaunal forms have a low biomass in this size-class range (Tweedale 1991). Duplisea \& Hargrave (1996) showed that epibenthic meiofauna were found in the Schwinghamer trough sizes and that these epibenthic organisms seem to be more sensitive to organic carbon pollution by salmon aquaculture. Therefore, by excluding the 0 to $1 \mathrm{~cm}$ layer, the potential masking of an infaunal bimodal pattern by the non-sediment-bound epifauna is removed. The BBSS pattern at all sites did not change appreciably with the removal of epibenthic organisms; therefore, we conclude that BBSS bimodality is not a feature of the purely infaunal benthos at any location in this study.

The present study does not conform to the theory that a bimodal biomass size spectrum necessarily results from the physical constraint of sediment pore space on benthic organism body size. Previous studies have shown that the species size spectrum has a similar shape to the biomass size spectrum at a location (Warwick 1984, Strayer 1986). Unfortunately, this type of analysis requires a high degree of taxonomic expertise, which was not available in this study; however; a crude taxonomic analysis suggested that a bimodal species size spectrum might exist in the Baltic (Duplisea 1998) contrary to the less consistent pattern in biomass size spectra observed in this study.

Though it is tempting to directly attribute observed biomass size spectrum patterns to derived species size spectrum patterns, there are at least 2 assumptions associated with the supposition: Firsty, each species carries with it a certain amount of biomass and hence more species in that system necessarily means more biomass. This is a tenuous assumption since it is known that species biomasses fluctuate considerably in time and space, while total biomass remains far more constant (Jones \& Lawton 1995). Secondly, most species size spectra which have been constructed assign 1 species uniquely to 1 body size class, usually average adult body size (Warwick 1984, Strayer 1986, Holling 1992, Kendall et al. 1997), and are, hence, a further abstraction of the system beyond biomass size spectra. This type of species size spectrum can be constructed simply with a species list and a single measure of body size for each species. To obtain an observed species size spectrum on par with the biomass size spectrum would require the number of species in each size class in a system ta be examined, allowing a species to be included in the tally as many times as the number of size classes in which it appears. This second type of species size spectrum requires data on the size distribution of each species in the system and therefore is more demanding. Mechanistic relationships between the species and biomass size spectra must be elucidated before it can be concluded that one type of spectrum results from the other.

The present work indicates that the overall biomass size spectrum of benthic organisms at these sites in the Askö area is not bimodal and does not vary consistently among sediments with different granulometric properties. Our work, therefore, corroborates neither the empirical BBSS patterns described by Schwinghamer (1981) nor the theory suggested to explain it. Studies in other areas in the Baltic Sea under a range of sediment granulometric conditions also indicate that bimodality is not a feature of Baltic Sea BBSS (Drgas et al. 1994, Duplisea 1998). Though a considerable number of contrary empirical patterns have been described since Schwinghamer's (1981) seminal work, none have challenged the theory directly and spectra bimodality is sometimes considered the norm, with the theory quoted as its cause.

Acknowledgements. We gratefully acknowledge the financial support of Stockholm's Marine Research Centre and grants from the Swedish Natural Science Research Council to Ragnar Elmgren. Thanks to the staff at the Askö lab who enabled us to carry out this research. We acknowledge the considerable contribution of Peter Schwinghamer to size spectra studies, and thank him for advice early in this work. Also, we thank Ragnar Elmgren for advice on the work and commenting on the manuscript. Susan Jensen commented on the manuscript.

\section{LITERATURE CITED}

Ankar S, Elmgren R (1976) The benthic macro- and meiofauna of the Askö-Landsort area (Northern Baltic Proper): a stratified random sampling survey. Contributions of the Askö Laboratory, StockhoIm University, No. 11

Blomqvist S, Abrahamsson B (1985) An improved Kajak-type gravity core sampler for soft bottom sediments. Schweiz Z Hydrol. 47:81-84

Bourassa N, Morin A (1995) Relationships between size structure of invertebrate assemblages and trophy and substrate composition in streams. J North Am Benthol Soc 14 : $393-403$

Drgas A, Warzocha J, Chmielowski H, Radziejewska T (1994) Constructing size spectra of benthic communities in the Gulf of Gdansk: d methodological approach. Bull Sea Fish Inst Gdynia 132:27-33

Duplisea DE (1998) Structuring of benthic communities, with a focus on size spectra. PhD thesis, Stockholm University

Duplisea DE, Hargrave BT (1996) Response of meiobenthic size-structure, biomass and respiration to sediment organic enrichment. Hydrobiologia 339:161-170

Elmgren R, Radziejewska $T$ (1989) Recommendations for quantitative benthic meiofauna studies in the Baltic. Baltic Marine Biologists Publication No. 12

Feller RJ, Warwick RM (1988) Energetics. In: Higgins RP, Thiel $\mathrm{H}$ (eds) Introduction to the study of meiofauna. Smithsonian Institution Press, Washington, DC, p 181-196

Gerlach SA, Hahn AE, Schrage M (1.985) Size spectra of benthic biomass and metabolism. Mar Ecol Prog Ser 26: $161-173$ 
Hanson JM, Prepas EE, Mackay WC (1989) Size distribution of the macroinvertebrate community in a freshwater lake. Can J Fish Aquat Sci 46:1510-1519

Holling CS (1992) Cross-scale morphology, geometry, and dynamics of ecosystems. Ecol Monogr 62:447-502

Holme NA, McIntyre AD (1984) Methods for the study of marine benthos, 2nd edn. Blackwell, Oxford

Jansson BO (1967) The significance of grain size and pore water content for the interstitial fauna of sandy beaches. Oikos 18:311-322

Jones CG, Lawton JH (1995) Linking species and ecosystems. Chapman and Hall, New York

Kendall MA, Warwick RM, Somerfield PJ (1997) Species size distributions in Arctic benthic communities. Polar Biol 17. 389-392

Macpherson E, Gordoa A (1996) Biomass spectra in benthic fish assemblages in the Benguela system. Mar Ecol Prog Ser 138:27-32

Morin A, Nadon D (1991) Size distribution of epilithic lotic invertebrates and implications for community metabolism. J North Am Benthol Soc 10:300-308

Ólafsson E, Elmgren R (1997) Seasonal dynamics of sublittoral meiobenthios in relation to phytoplankton sedimentation in the Baltic Sea. Estuar Coast Shelf Sci 45:149-164

Poff NL, Palmer MA, Angermeier PL, Vadas RL Jr, Hakenkamp CC, Bely A, Arensburger P, Martin AP (1993) Size structure of the metazoan community in a Piedmont stream. Oecologia 95:202-209

Rumohr H, Brey T, Ankar S (1987) A compilation of biometric conversion factors for benthic invertebrates of the Baltic Sea. Baltic Marine Biologists Rep No. 9

Editorial responsibility: Otto Kinne (Editor),

Oldendorf/Luhe, Germany
Schwinghamer P (1981) Characteristic size distributions of integral benthic communities. Can J Fish Aquat Sci 38: $1255-1263$

Schwinghamer P (1983) Generating ecological hypotheses from biomass spectra using causal analysis: a benthic example. Mar Ecol Prog Ser 13:151-166

Silvert W (1996) Size-aggregation models of aquatic ecosy'stems. Sci Total Environ 183:107-114

Snelgrove PVR, Butman CA (1994) Animal sediment relationships revisited - cause versus effect. Oceanogr Mar Biol Annu Rev 32:111-177

Strayer D (1986) The size structure of a lacustrine zoobenthic community. Oecologia 69:513-516

Strayer DL, May SE, Nielsen P, Wollheim W, Hausam S (1997) Oxygen, organic matter, and sediment granulometry as controls on hyporheic animal communities. Arch Hydrobiol 140:131-144

Tweedale WA (1991) Size spectrum analyses of harpacticoid copepods and other crustaceans at two seagrass sites. MSc thesis, University of South Florida, Tampa

Warwick RM (1984) Species size distributions in marine benthic communities. Oecologia 61:32-41

Warwick RM, Joint IR (1987) The size distribution of organisms in the Celtic Sea: from bacteria to Metazoa. Oecologia 73:185-191

Weiser W (1959) The effect of grain size on the distribution of small invertebrates inhabiting the beaches of Puget Sound. Limnol Oceanogr 4:181-194

Williams R (1972) The abundance and biomass of the interstitial fauna of a graded series of shell-gravels in relation to the available space. J Anim Ecol 41:623-646

Submitted: July 27, 1998; Accepted: October 26, 1998

Proofs received from author(s): January 21, 1999 